\title{
A novel anti-adhesion peptide ( $\beta 3$ ) inhibits hepatocellular carcinoma activity in vitro and in vivo
}

\author{
SONGMEI WANG ${ }^{1}$, JUN ZHU ${ }^{2}$ and YINKUN LIU ${ }^{3}$ \\ ${ }^{1}$ Laboratory of Molecular Biology, Experimental Teaching Center of Basic Medicine, \\ Fudan University, Shanghai 200032; ${ }^{2}$ Department of Pharmacy, Shanghai Chest Hospital, Shanghai 200031; \\ ${ }^{3}$ Liver Cancer Institute, Fudan University, Shanghai 200032, P.R. China
}

Received October 28, 2014; Accepted April 15, 2016

DOI: $10.3892 / \mathrm{ol} .2016 .5277$

\begin{abstract}
The present study aimed to investigate the blocking of tumor cell adhesion to the extracellular matrix, the prevention of tumor metastasis by the $\beta$ peptide trimer $\beta 3$, as well as the influence of $\beta 3$ on the recurrence and survival time of hepatocellular carcinoma (HCC) nude mice model LCI-D20 after early resection. To this end, the DNA fragment of the $\beta 3$ peptide (DLYYLMDLSYSMKGGDLYYLMDL SYSMKGGDLYYLMDLSYSMK) was cloned into the expression vector $\mathrm{pET}$-His and the fusion protein His- $\beta 3$ was expressed in E. coli BL21 (DE3) plysS. The anti-adhesion effect of $\beta 3$ on the highly metastatic HCC cell line HCCLM6 to fibronectin (FN) was measured by MTT assay. The inhibition of HCCLM6 cell invasion by $\beta 3$ was analyzed using a Transwell (modified Boyden chamber) system and Matrigel. The influence of $\beta 3$ on the recurrence of HCC and mouse survival time after early resection was investigated using the HCC metastasis nude mice model LCI-D20. HCCLM6 cells incubated with $10,20,50$ or $100 \mu \mathrm{mol} / 1 \beta 3$ for $3 \mathrm{~h}$ demonstrated a marked reduction in adhesion to FN. The adhesion inhibition rates were $11.8,21.7,37.5$ and $66.4 \%$, respectively. In addition, cell invasion was reduced by $51.3 \%$ in HCCLM6 cells cultured with $100 \mu \mathrm{mol} / 1 \beta 3$. Treatment with $\beta 3$ also inhibited tumor recurrence at the incisal edge and prolonged the survival time of LCI-D20 mice following early resection. The present study provided evidence that $\beta 3$ peptide specifically blocked the adhesion and invasion of HCCLM6 cells, inhibited HCC recurrence in vivo and prolonged the survival time of HCC nude mice LCI-D20 following hepatectomy. Therefore, $\beta 3$ may be further investigated as a novel anti-tumor drug.
\end{abstract}

Correspondence to: Professor Yinkun Liu, Liver Cancer Institute, Fudan University, 4th Building, 180 Fenglin Road, Shanghai 200032, P.R. China

E-mail: liu.yinkun@zs-hospital.sh.cn

Key words: trimer $\beta$ peptide, hepatocellular carcinoma, anti-adhesion, invasion, recurrence

\section{Introduction}

Hepatocellular carcinoma (HCC) is the third leading cause of cancer mortality worldwide. In 2010, liver cancer resulted in 754,00 mortalities, representing an increase of $62.4 \%$ since 1990. Despite significant advances in the treatment and the prevention of postoperative metastasis, the 5-year postoperative recurrence rate of $\mathrm{HCC}$ remains high and the recurrence and metastasis of $\mathrm{HCC}$ also remains a problem in clinical practice $(1,2)$. Efforts have been made to develop more efficient drugs to inhibit and prevent tumor metastasis. Cancer metastasis involves tumor cells dissociating from the primary locus, invading the surrounding tissue, entering and extravasating from the circulation, and growing in distant organs $(3,4)$. During this complex process, cell adhesion is one of the most important events (5). A number of previous studies have focused on synthesized anti-adhesion peptides (6-8). However, the application of these short peptides is limited due to their short half-life and high dosage required. To prolong the half-life of synthesized peptide, multimers and derivatives were designed (9-11). It has been demonstrated that the anti-metastasis effect of multimers of synthesized peptides was stronger than that of monomer peptides $(12,13)$.

Integrins are a family of adhesion molecules located on cells and in the extracellular matrix. The expression levels of integrins are closely associated with the migration ability of cells (14). The anti-adhesion peptide $\beta$ (DLYYLMDLSYSMK, $\beta 1)$ was designed by Liu et al based on the conserved sequence of the integrin a and $\beta$ units (15). In our previous study, this peptide was shown to block the interaction between HCC cells and the extracellular matrix, in addition to inhibiting intrahepatic and pulmonary metastases following carcinosectomy in a nude mouse model with human HCC that has high metastatic potential (LCI-D20) $(16,17)$. On the basis of these studies, the trimeric peptide $\beta$ ( $\beta 3$ ) was designed. The present study aimed to determine the effects of $\beta 3$ on the adhesive properties of the human liver cancer cell line HCCLM6 to fibronectin (FN), the invasion of HCCLM6 cells through reconstituted basement membrane. In addition the rate of liver cancer recurrence and LCI-D20 mouse survival time following early carcinosectomy were investigated. 


\section{Materials and methods}

Design and production of $\beta 3$. The anti-adhesion trimeric $\beta$ peptide (DLYYLMDLSYSMKGGDLYY LMDLSYSMKGGDLYYLMDLSYSMK, $\beta 3$ ) was expressed in $E$. coli as described previously (18). Briefly, the DNA fragment of $\beta 3$ (Sangon Biotech Co., Ltd., Shanghai, China) was cloned into the pET-His expression vector (Gene Power Lab Ltd., Shenzhen, China) and the fusion protein His- $\beta 3$ was expressed in E. coli BL21 (DE3) plysS (Gene Power Lab Ltd.). Following $1.5 \mathrm{~h}$ of induction with isopropyl- $\beta$-D-thiogalactoside (GE Healthcare Bio-Sciences, Pittsburgh, PA, USA), $20 \mathrm{mg}$ of $\beta 3$ peptide was obtained from $1 \mathrm{~L}$ of culture medium following purification with metal-chelating sepharose 6B FF (Vector Gene Technology Company Ltd., Beijing, China). The purity of $\beta 3$ was $92.2 \%$ according to Gel-Pro Analyzer 3.1 software (Media Cybernetics, Inc., Rockville, MD, USA).

Cell culture. The highly metastatic HCC cell line HCCLM6, was initially established and preserved by the Liver Cancer Institute, Fudan University (Shanghai, China) and was cultured in Gibco Dulbecco's modified eagle's medium (DMEM, Thermo Fisher Scientific, Inc., Waltham, MA, USA) supplemented with $10 \%$ fetal bovine serum (Thermo Fisher Scientific, Inc.), $100 \mathrm{U} / \mathrm{ml}$ penicillin at $37^{\circ} \mathrm{C}$ under an atmosphere of $5 \% \mathrm{CO}_{2}$. The medium was replenished every 3 days to maintain cell growth.

Coating the 96-well high binding microplate with FN. FN (Sigma-Aldrich, St. Louis, MO, USA) solution (containing $10 \mu \mathrm{g} / \mathrm{ml} \mathrm{FN,} 20 \mathrm{mmol} / 1$ Tris-Cl, $\mathrm{pH}$ 7.4, $150 \mathrm{mmol} / 1 \mathrm{NaCl}$, $1 \mathrm{mmol} / 1 \mathrm{MgCl}_{2}, 1 \mathrm{mmol} / 1 \mathrm{CaCl}_{2}, 1 \mathrm{mmol} / 1 \mathrm{MnCl}_{2}$ ) was added to a 96 -well high binding microplate $(100 \mathrm{ml}$ per well), and incubated at $4^{\circ} \mathrm{C}$ overnight. The plate was then incubated with blocking buffer (10 mmol/l Hepes, $\mathrm{pH} 7.4,140 \mathrm{mmol} / \mathrm{l} \mathrm{NaCl}$, $5.4 \mathrm{mmol} / 1 \mathrm{KCl}, 5.56 \mathrm{mmol} / 1 \mathrm{glucose}, 3 \% \mathrm{BSA}, 1 \mathrm{mmol} / \mathrm{l}$ $\mathrm{MgCl}_{2}, 2 \mathrm{mmol} / \mathrm{l} \mathrm{CaCl}_{2}, 1 \mathrm{mmol} / 1 \mathrm{MnCl}_{2}$ ) at $37^{\circ} \mathrm{C}$ for $2 \mathrm{~h}$, and air dried for future use.

Cell adhesion assay. A total of $100 \mu \mathrm{l}$ of HCCLM6 cell suspension $\left(2 \times 10^{5}\right.$ cells $\left./ \mathrm{ml}\right)$ was plated in each well of an FN-coated 96-well high binding microplate. A total of $100 \mathrm{ml}$ of DMEM medium containing $\beta 3$ at concentrations of $20,40,100$ or $200 \mu \mathrm{mol} / \mathrm{l}$ was added at the same time. The final concentrations of $\beta 3$ were $10,20,50$ or $100 \mu \mathrm{mol} / 1$, respectively. The same volume of cell culture medium without $\beta 3$ was added to the control group and $200 \mathrm{ml}$ of cell culture medium only was added in the plate for the blank group. The assay was conducted in quintuplicate for each sample. Following incubation for $3 \mathrm{~h}$ at $37^{\circ} \mathrm{C}$ in $5 \% \mathrm{CO}_{2}$, the unattached cells were gently washed away with HANKS buffer (Sangon Biotech Co., Ltd.). The attached cell number in each well was measured using the MTT assay (see below). The inhibition rate of $\beta 3$ on cell adhesion to FN was calculated with the following equation: Cell adhesion inhibition rate $=$ (average OD of control well - average OD of $\beta 3$-treated well) / (average OD of control well - average OD of blank well) x $100 \%$.

MTT assay. The number of attached cells in each well was analyzed by the MTT assay, and quantified by a micro-titer plate reader (Amersham, USA). Briefly, $100 \mu \mathrm{l}$ DMEM and $20 \mu \mathrm{l}$
Table I. The inhibitory effects of $\beta 3$ on the invasion of HCCLM6 cells $(n=5)$.

\begin{tabular}{lcc}
\hline Group & $\begin{array}{c}\text { Invaded cells } \\
(\text { mean } \pm \text { SD) }\end{array}$ & $\begin{array}{c}\text { Invasion inhibitory } \\
\text { rate }(\%)\end{array}$ \\
\hline Control group & $22.6 \pm 4.77$ & - \\
$\beta 3$ group & $11 \pm 2.74^{\mathrm{a}}$ & 51.3 \\
\hline
\end{tabular}

${ }^{\text {a }}<<0.05$, compared with control group.

MTT (5 mg/ml; Sigma-Aldrich) were added to each well. After incubation at $37^{\circ} \mathrm{C}$ for $4 \mathrm{~h}$, the medium and MTT was discarded. A total of $200 \mu \mathrm{l}$ of $0.04 \mathrm{~mol} / 1$ hydrogen chloride-2-propanol solution was added to each well. The amount of MTT formazan product, which reflects the number of cells adhering to $\mathrm{FN}$, was determined by measuring absorbance with a microplate reader at a wavelength of $570 \mathrm{~nm}$ and a reference wavelength of $630 \mathrm{~nm}$.

Invasion assay. The invasion assay was performed as described previously (19). Briefly, the upper portions of Transwell chambers (Corning, New York, NY, USA) were coated with $75 \mu \mathrm{l}$ of Matrigel (BD Biosciences, Franklin Lakes, NJ, USA) diluted 1:10 in serum-free DMEM and incubated at $37^{\circ} \mathrm{C}$ for $2 \mathrm{~h}$. The supernatants of HCCLM6 cells cultured with DMEM containing $10 \%$ FCS were harvested once the cells had grown to confluence, and after the addition of $\mathrm{FN}$ at a final concentration of $5 \mu \mathrm{g} / \mathrm{ml}$, resulting in conditioned medium. The cells were harvested by trypsinization and diluted to a $2 \times 10^{6} / \mathrm{ml}$ cell suspension with serum-free DMEM. A total of $100 \mu \mathrm{l}$ of the cell suspension and $100 \mu \mathrm{l}$ of $200 \mu \mathrm{mol} / \mathrm{l} \beta 3$ peptide in serum-free DMEM (or serum-free DMEM only as a control) were added in the upper chambers. Then, $600 \mu \mathrm{l}$ of conditioned medium was added to the bottom chamber of the Transwell plate. After incubation at $37^{\circ} \mathrm{C}$ for $48 \mathrm{~h}$ under a $5 \% \mathrm{CO}_{2}$ atmosphere, the non-invading cells and the gel were gently removed from the upper chamber with cotton-tipped swabs. After rinsing with PBS, cells on the filters were fixed with formaldehyde and stained in Giemsa staining solution for $30 \mathrm{~min}$. The number of invaded cells on the filters were counted in five randomly selected high-powered (x200) fields per filter under a microscope (Leica, Heerbrugg, Switzerland). The invasion inhibition rate was calculated using the following equation: Invasion inhibition rate $=[1$ - (invaded cell number in $\beta 3$ chamber / invaded cell number in control chamber)] x $100 \%$.

Animal model and treatment. A total of 246 -week-old male BALB/cA nude mice were obtained from the Shanghai Institute of Materia Medica, Chinese Academy of Sciences (Shanghai, China). A tumor block from tumor-bearing mice was implanted into the left lobe of the nude mouse liver as described previously (20). Briefly, a left upper abdominal transverse incision was made under anesthesia. The left lobe of the liver was exposed and a part of the liver surface was mechanically injured with scissors. Next, a tumor block of $0.2 \times 0.2 \times 0.2 \mathrm{~cm}$ was fixed within the liver tissue. After the surgery, mice were kept in laminar-flow cabinets under pathogen-free conditions and given 
Table II. Liver cancer recurrence after early resection.

\begin{tabular}{lccc}
\hline Group & $\begin{array}{c}\text { Number of mice } \\
\text { examined }\end{array}$ & $\begin{array}{c}\text { Weight of recurrent } \\
\text { lesions (mean } \pm \text { SD) }\end{array}$ & $\begin{array}{c}\text { Number of mice } \\
\text { with recurrent lesions }\end{array}$ \\
\hline Control group & 6 & $2.31 \pm 1.57^{\mathrm{a}}$ & 6 \\
$\beta 3$ group & 6 & $0.17 \pm 0.26^{\mathrm{ab}}$ & 2 \\
\hline
\end{tabular}

${ }^{\mathrm{a}}$ weight in grams; ${ }^{\mathrm{P}}<0.05$, compared with control group.

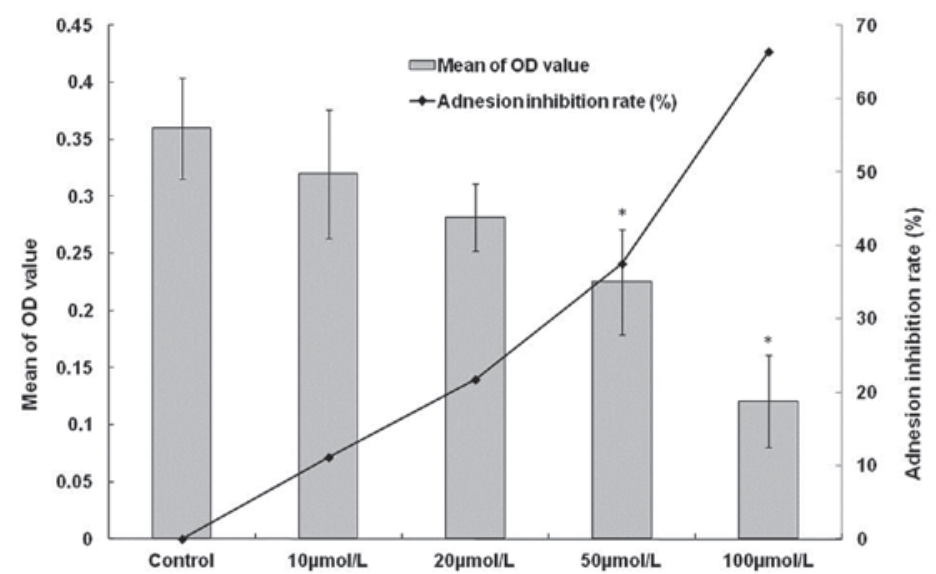

Figure 1. The inhibitory effect of $\beta 3$ on the adhesion of HCCLM6 cells to fibronectin (n=5). HCCLM6 cells incubated with $10,20,50$ and $100 \mu$ mol/1 $\beta 3$ for $3 \mathrm{~h}$ exhibited a marked reduction in cell adhesion. The adhesion inhibition rates were $11.8,21.7,37.5$ and $66.4 \%$, respectively. ${ }^{*} \mathrm{P}<0.05$, compared with control group.

free access to food and water. Liver cancer early resection was performed at $0.2 \mathrm{~cm}$ from the edge of the tumor at day 10 following implantation, prior to metastasis.

Measurement of tumor recurrence and mouse survival time. Animals were randomly assigned to 2 groups (each group, $n=12$ ). At day 1 following resection, the animals were subcutaneously administrated $100 \mu \mathrm{l}$ of $1 \mathrm{mg} / \mathrm{ml}$ of $\beta 3$ or normal saline (NS) as a control every other day for 10 doses. Half of the mice $(n=6)$ in each group were sacrificed at day 55 post-implantation with an overdose of $6 \%$ chloral hydrate $(0.5 \mathrm{ml} / 100 \mathrm{~g}$ of body weight; Sigma-Aldrich). At autopsy, the viscera of the animals were examined macroscopically. If recurrence of tumors at the incisal margin was observed, the lesions were resected and weighed.

The other 6 mice of each group were housed in pathogen-free cages. Each animal was examined daily until death. The number of days that each animal survived following resection was recorded. Survival curves were constructed using the Kaplan-Meier method.

All animal experiments were conducted in strict accordance with the National Institute of Health Guide for the Care and Use of Laboratory Animals. This study was approved by the Experimental Animal Ethics Committee of Shanghai Medical College, Fudan University (approval no. 20021101).

Statistical analysis. All data were entered into Excel spreadsheets (Excel, Microsoft, Seattle, USA). Statistical analysis was performed using Student's $t$-test, or the Mann Whitney U test when the data were not normally distributed. Values of $\mathrm{P}<0.05$ in a two-tailed fashion were considered to indicate a statistically significant difference. All analyses were performed using SAS (SAS Institute Inc., Cary, NC, USA).

\section{Results}

The inhibitory effect of $\beta 3$ on the adhesion of HCCLM6 cells to FN. HCCLM6 cells incubated with 10, 20, 50 and $100 \mu \mathrm{mol} / 1$ $\beta 3$ for $3 \mathrm{~h}$ exhibited a marked reduction in cell adhesion. The adhesion inhibition rates were $11.8,21.7,37.5$ and $66.4 \%$, respectively (Fig. 1). These findings indicate that $\beta 3$ is able to inhibit the adhesion of HCCLM6 cells to FN, and $\beta 3$ may obstruct the invasion of HCC cells to paratumor liver parenchyma.

The inhibitory effect of $\beta 3$ on the invasion ability of HCCLM6 cells. Following incubation with $100 \mu \mathrm{mol} / 1 \beta 3$, the number of invaded HCCLM6 cells was reduced significantly, with an inhibition rate of $51.3 \%$ (Table I). Therefore, $\beta 3$ may block HCC cells from invading the surrounding tissue and entering and extravasating from the circulation in vivo.

The influence of $\beta 3$ on the intrahepatic recurrence of the LCI-D20 model following early resection. On the 10th day post-tumor-implantation, LCI-D20 tumors were resected, and $\beta 3$ or the same volume of NS was subcutaneously injected. On day 55, mice were sacrificed to check for intrahepatic recurrence. The recurrent tumors were located around the incisal margins. There were $2(2 / 6)$ mice with intrahepatic recurrent tumors in the $\beta 3$ group, while there were $6(6 / 6)$ mice with 


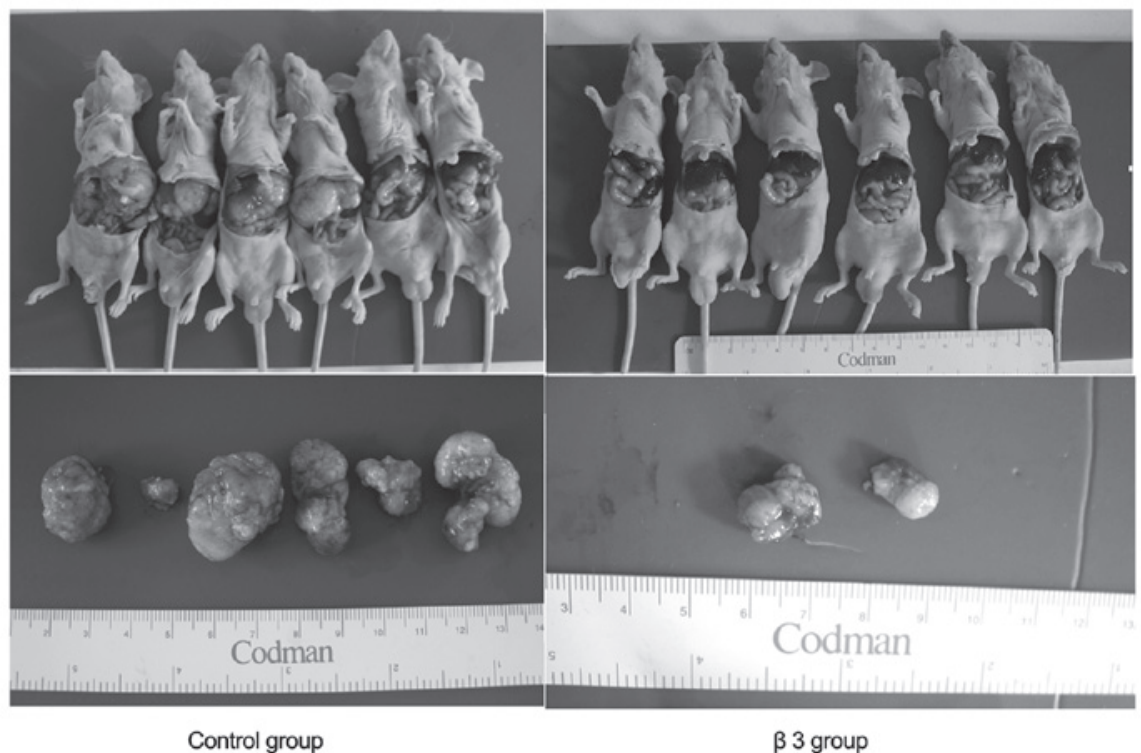

Figure 2. Liver cancer recurrence at the incisal margins after early resection. On the 10 th day post-tumor-implantation, LCI-D20 tumors were resected, and $\beta 3$ or the same volume of saline was subcutaneously injected. On day 55, mice were sacrificed to check for intrahepatic recurrence. A total of $2 / 6$ mice developed intrahepatic recurrent tumors in the $\beta 3$ group, while 6/6 mice developed intrahepatic recurrent tumors in the control group. Compared with the control group, the weights of recurrent tumors of the $\beta 3$ group were markedly reduced.

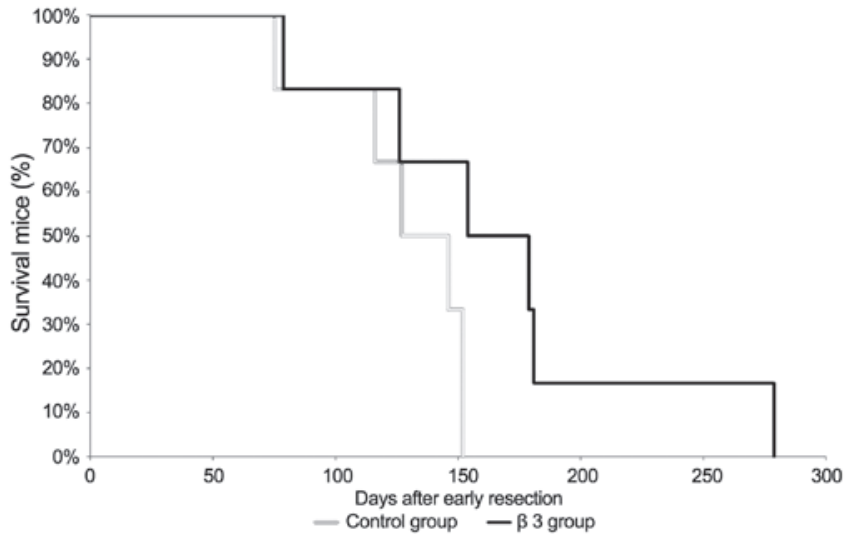

Figure 3. Kaplan-Meier analysis of mouse survival time following early resection. At day 1 after resection, the animals were subcutaneously administrated $100 \mu \mathrm{l}$ of $1 \mathrm{mg} / \mathrm{ml}$ of $\beta 3$ or saline alone as a control every other day for 10 doses. The median survival times after early resection were $136.5 \mathrm{~d}$ (control group) and $166.5 \mathrm{~d}$ ( $\beta 3$ group), respectively.

intrahepatic recurrent tumors in the control group (Fig. 2 and Table II). Compared with the control group, the weight of recurrent tumors of the $\beta 3$ group were markedly reduced. These results indicate that $\beta 3$ may have inhibitory effects on tumor recurrence at the incisal margin.

Survival analysis of LCI-D20 mice after early resection. Twelve animals were randomly assigned to 2 groups (each group, $n=6$ ). At day 1 following resection, the animals were subcutaneously administrated $100 \mu \mathrm{l}$ of $1 \mathrm{mg} / \mathrm{ml}$ of $\beta 3$ or NS as a control every other day for 10 doses. The mice were housed in pathogen-free cages, and given free access to autoclaved food and water. The survival curves were constructed using the Kaplan-Meier method (Fig. 3). The median survival times after early resection were 136.5 days (control group) and 166.5 days ( $\beta 3$ group), respectively. This result indicates that $\beta 3$ treatment prolonged the survival time of mice following early resection.

\section{Discussion}

The adhesion molecules on the surface of both tumor cells and endothelial cells are associated with tumor metastasis and recurrence. Blocking the interaction between tumor cell adhesion molecules and their ligands is a major strategy to prevent cancer metastasis $(21,22)$. A number of previous studies have focused on the synthesized anti-adhesion peptides $(13,23)$. One such peptide is RGD, derived from the common conserved sequence of the main matrix proteins such as fibronectin, collagen and fibrinogen $(24,25)$. A second peptide is YIGSR, which originates from the basement membrane protein laminin (26). The third peptide is EILDV, which stems from the core sequence of fibronectin (27). The application of these short peptides is limited due to their short half-life, ease of degradation and the requirement for a high dosage. To prolong the peptides' half-lives, multimers and derivatives of these peptides were designed (28). The anti-metastasis effect of multimers of synthesized peptides was stronger compared to peptide monomers. The more times the sequence is repeated, the stronger the anti-metastasis effect is.

$\mathrm{FN}$ is an important cell adhesion molecule in the extracellular matrix. It mediates cell adhesion and migration, and serves a significant role in tumor invasion and metastasis (29). Examination of tumor cell adhesion to $\mathrm{FN}$ is a common method for studying tumor cell metastasis. In the present study, the extracellular matrix was simulated by coating cell culture plates with FN, after which the inhibitory effects of $\beta 3$ peptide on liver cancer cell adhesion to FN were investigated. The results demonstrated that after treatment of HCCLM6 cells with $\beta 3$ peptide for $3 \mathrm{~h}$, an inhibitory effect on cell adhesion to FN was observed. There are two possible mechanisms by which 
$\beta 3$ peptide blocked tumor cell adhesion to FN. First, the $\beta 3$ peptide may occupy the integrin binding site through binding to the RGD sequence of the matrix protein. Second, $\beta 3$ may also interact with integrin because $\beta 3$ was designed based on the conserved sequence of the integrin $\alpha$ and $\beta$ units.

During metastasis, tumor cells must penetrate the basement membrane through three steps: Dislodging from the original site, entering blood circulation, and migrating from blood flow into remote sites (30). Matrigel, used as an artificial basement membrane matrix, is produced from mouse Engelbreth-Holm-Swarm sarcoma rich in extracellular matrix protein (31). The artificial basement membrane is plated on a Millipore filter in Transwell culture chambers, and forms a membrane structure similar to natural basement membrane. Invasive tumor cells can penetrate the membrane under the induction of chemotactics, simulating the invasion of tumor cells through the basement membrane in vivo. The results indicated that $\beta 3$ exerted significant inhibitory effects on the invasion of HCCLM6 cells.

In addition, the anti-tumor effect of $\beta 3$ was observed in vivo. In LCI-D20 mice, $\beta 3$ treatment was shown to reduce the weights of recurrent tumors at the incisal margins, in addition to the number of mice with intrahepatic recurrent tumors after early resection. Notably, $\beta 3$ prolonged the survival time of LCI-D20 mice after early hepatectomy.

Metastasis and recurrence of liver cancer are major determinants for the prognosis and long-term survival of liver cancer patients. Polypeptide therapy is a newly developed treatment for tumors. Taken together, these cell and animal studies demonstrated that the $\beta 3$ peptide had anti-adhesion and anti-recurrence effects, in addition to the capability to prolong survival time after early resection. Therefore, the $\beta 3$ peptide is worthy of further investigation as a potential drug for blocking tumor metastasis and recurrence.

\section{References}

1. Fang WQ, Li SP, Zhang CQ, Xu L, Shi M, Chen MS and Li JQ Prophylaxis and clinical treatment for surgical margin recurrence of small primary hepatocellular carcinoma. Ai Zheng 24: 834-836, 2005.

2. Zhi X, Lin L, Yang S, Bhuvaneshwar K, Wang H, Gusev Y, Lee MH, Kallakury B, Shivapurkar N, Cahn K, et al: $\beta$ II-spectrin (SPTBN1) suppresses progression of hepatocellular carcinoma and Wnt signaling by regulation of Wnt inhibitor kallistatin. Hepatology 61: 598-612, 2015.

3. Wyke JA: Overview-burgeoning promise in metastasis research. Eur J Cancer 36: 1589-1594, 2000

4. Liotta LA, Steeg PS and Stetler-Stevenson WG: Cancer metastasis and angiogenesis: An imbalance of positive and negative regulation. Cell 64: 327-336, 1991.

5. Chu XY and Chen LB: Cellular adhesive molecular and the invasion and metastasis of neoplasm. Yixue Yanjiusheng Xuebao 13: 42-45, 2000.

6. Li FH: The inhibitory effect of bioactive peptides on neoplasm metastasis. Kouqiang Hemian Waike Zazhi 9: 231-234, 1999.

7. Liu LY, Chen ZY and Zhao TH: Investigations of a peptide with RGD and YIGSR fragments: Synthesis and its anti-tumor invasion activities. Zhongguo Xinyao Zazhi 14: 729-731, 2005.

8. Saiki I, Yoneda J, Kobayashi H, Igarashi Y, Komazawa H, Ishizaki Y, Kato I and Azuma I: Antimetastatic effect by anti-adhesion therapy with cell-adhesive peptide of fibronectin in combination with anticancer drugs. Jpn J Cancer Res 84: 326-335, 1993.

9. Liu LY, Chen ZY and Zhao TH: Synthesis of RGD identical-fork-peptide derivative with inhibitive effecton adhesiveness of advanced metastatic tumor cells. Zhongguo Xinyao Zazhi 15: $1661-1663,2006$.
10. Zhang HQ, Shinohara H, Gu N, Sasaki H and Sisido M: Cell adhesion inhibition by RGD peptides linked with a photoisomerizable nonnatural amino acid. J Southeast Univ 17: 22-26, 2001.

11. Zhao M, Wang C, Jiang X and Pen S: Synthesis of RGD containing peptides and their bioactivities. Prep Biochem Biotechnol 32: 363-380, 2002.

12. Cao K, Zhao TH, Chen ZY, Gao W, Yang HS and Shi B: The invasive capacity of human lung great cellular xancerous PG cells on reformed basement membrane and inhibition of synthetic peptides. Zhongliu Fangzhi Yanjiu 29: 20-22, 2002.

13. Okrój M, Dobrzańska-Paprocka Z, Rolka K and Bigda J: In vitro and in vivo analyses of the biological activity of RGD peptides towards Ab Bomirski melanoma. Cell Mol Biol Lett 8: 873-884, 2003.

14. Liu J, Guo SX and Tang JG: Research progress of RGD-peptide for cancer therapy. Guowai Yixue (Zhongliuxue Fence) 30: 193-197, 2003.

15. Liu YK, Nemoto A, Feng Y and Uemura T: The binding ability to matrix proteins and the inhibitory effects on cell adhesion of synthetic peptides derived from a conserved sequence of integrins. J Biochem 121: 961-968, 1997.

16. Uemura T, Nemoto A and Liu YK: Synthetic peptide derived from a conserved sequence of integrin $\beta$ subunit. Res Adv in Biosci \& Bioeng 23: 65-83, 2000.

17. Sun JJ, Zhou XD, Liu YK, Tang ZY, Sun RX, Zhao Y and Uemura T: Inhibitory effects of synthetic beta peptide on invasion and metastasis of liver cancer. J Cancer Res Clin Oncol 126: 595-600, 2000

18. Wang SM, Zhu J, Li Y, Pan LF, Zha XL and Liu YK: Molecular cloning and expression of anti-tumor adhesion peptide (beta3). Sheng Wu Gong Cheng Xue Bao 21: 558-562, 2005 (In Chinese).

19. Knutson JR, Lida J, Fields GB and McCarthy JB: CD44/chondroitin sulfate proteoglycan and alpha 2 beta 1 integrin mediate human melanoma cell migration on type IV collagen and invasion of basement membranes. Mol Biol Cell 7: 383-396, 1996.

20. Sun FX, Tang ZY, Lui KD, Ye SL, Xue Q, Gao DM and Ma ZC: Establishment of a metastatic model of human hepatocellular carcinoma in nude mice via orthotopic implantation of histologically intact tissues. Int J Cancer 66: 239-243, 1996.

21. Syrigos KN and Karayiannakis AJ: Adhesion molecules as targets for the treatment of neoplastic diseases. Curr Pharm Des 12: 2849-2861, 2006.

22. Jiang CG and Xu HM: Research and application of anti-adhesion therapy in cancer metastasis. Guowai Yixue (Zhongliuxue Fence) 32: 31-34, 2005.

23. Wang YH, Liu YK, Li WC, Ye SL and Tang ZY: Inhibitory effect of anti-adhesion peptides on invasion/metastasis ability of hepatocellular carcinoma cells. Zhonghua Shiyan Waike Zazhi 21: 1168-1169, 2004

24. Liu YK, Wu WZ, Wu X, Jiang Y and Zhou XD: Liver cancer metastasis and signal transduction. In: Tang ZY. Metastasis and recurrence of hepatocellular carcinoma-basic and clinical studies. Shanghai Shanghai Scientific and technological education public house: 93-104, 2003.

25. Maeda M, Izuno Y, Kawasaki K, Kaneda Y, Mu Y, Tsutsumi Y, Nakagawa $S$ and Mayumi T: Amino acids and peptides. XXXI. Preparation of analogs of the laminin-related peptide YIGSR and their inhibitory effect on experimental metastasis. Chem Pharm Bull (Tokyo) 46: 347-350, 1998

26. Kaneda Y, Yamamoto Y, Okada N, Tsutsuml Y, Nakagawa S, Kakiuch M, Maeda M, Kawasaki K and Mayumi T: Antimetastatic effect of synthetic Glu-Ile-Leu-Asp-Val peptide derivatives containing D-amino acids. Anticancer Drugs 8: 702-707, 1997.

27. Feng ZH, Huang B, Zhang GM, Li D and Wang HT: Inducement of antitumor-immunity by DC activated by $\mathrm{Hsp} 70-\mathrm{H} 22$ tumor antigen peptide. Chinese Journal of Cancer Research 15: 79-85, 2003.

28. Wang SM, Zhu J, Li Y, Pan LF, Zha XL and Liu YK: Inhibitory effects of $\beta$ peptide and polymeric $\beta$ peptide on adhesion of hepatocellular carcinoma cells to fibronectin. Shiyong Zhongliu Zazhi 21: 223-226, 2005

29. Li NF, Gemenetzidis E, Marshall FJ, Davies D, Yu Y, Frese K, Froeling FE, Woolf AK, Feakins RM, Naito Y, et al: RhoC interacts with integrin $\alpha 5 \beta 1$ and enhances its trafficking in migrating pancreatic carcinoma cells. PLoS One 8: e81575, 2013.

30. Sengupta $\mathrm{N}$ and MacDonald TT: The role of matrix metalloproteinases in stromal/epithelial interactions in the gut. Physiology (Bethesda) 22: 401-409, 2007.

31. Benton G, Arnaoutova I, George J, Kleinman HK and Koblinski J: Matrigel: From discovery and ECM mimicry to assays and models for cancer research. Adv Drug Deliv Rev 79-80: 3-18, 2014. 